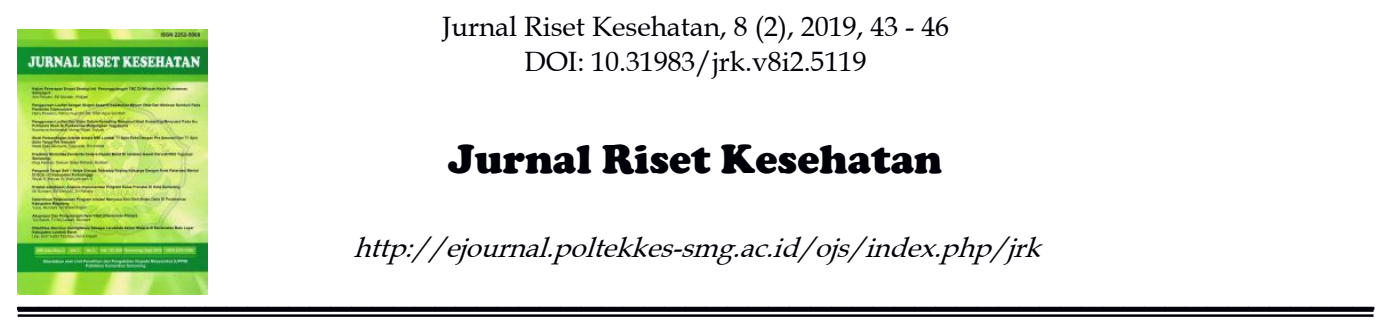

\title{
DECREASED PAIN SCALE BASED ON CRITICAL PAIN OBSERVATION TOOL (CPOT) AND BEHAVIORAL PAIN SCALE NON-INTUBATED (BPS-NI) IN PATIENTS WITH REDUCED CONSCIOUSNESS BY CLASSICAL MUSIC INTERVENTION IN UNS HOSPITAL
}

\author{
Muchtar Hanafi $^{\mathrm{a}^{*}} ;$ Faizal Muhammad $^{\mathrm{b}} ;$ Nanang Wiyono $^{\mathrm{c}}$; Betty Saptiwi ${ }^{\mathrm{d}}$ \\ a,b,c,d Universitas Sebelas Maret ; Ir. Sutami 36 A ; Surakarta ; Indonesia
}

\begin{abstract}
Patient with reduced consciousness needs attention to their comfort as well as pain during treatment. Listening to classical music caused relaxation and pain reduction. This study aimed to determine the effect of classical music on the CPOT score, BPS-NI, and cortisol levels in patients with reduced consciousness. The research was conducted by using a pretest-posttest control group design. 18 patients were divided into the control group (C) and the classical music group (M). Classical music was played for 3 days respectively that consisted of 3 sessions per day. Furthermore, each patient was tested for cortisol levels on the third day. Comparative test of mean difference between pre-intervention and post-intervention obtained significant results in CPOT $(p=0.000)$ and BPS-NI $(p=0.001)$ measurements in all groups. Tukey's post-hoc test obtained significant results in which the $\mathrm{M}$ group had a lower mean score. The mean of cortisol level was higher in M group $(14.7 \mu \mathrm{g} / \mathrm{dL})$ compared to the $\mathrm{C}$ group $(12.96 \mu \mathrm{g} / \mathrm{dL})$, although not significant statistically $(p=0.67)$. Listening to classical music for patients with reduced consciousness decreased the pain scale. This was supported by the average of cortisol levels that were higher in the $\mathrm{M}$ group, considering that cortisol was a hormone that prevents pain.
\end{abstract}

Keywords: reduced consciousness ; critical pain observation tool ; behavioral pain scale non-intubated; classical music ; cortisol

\section{Introduction}

In the era of patient-centered treatment, hospitals are demanded to be able to provide excellent services. Humans as complex creatures need not only to be served by professional medical personnel and complete infrastructure, but also to be managed holistically by considering physical, psychological, and social factors.

Pain is an unpleasant perception experienced by someone due to trauma, both physical and psychological trauma. Patients with decreased consciousness can still experience pain, discomfort, and anxiety (Georgiou et al., 2015). These aspects sometimes get less attention in the treatment for patients with reduced consciousness.

Despite reduced consciousness, the patient's

*) Corresponding Author (Muchtar Hanafi)

Email : muchtar.hanafi@staff.uns.ac.id auditory function is still intact with the surrounding environment (Gorji et al., 2014). This is the basis for various studies on therapeutic communication in patients with reduced consciousness, through identification of pain level (Heiderscheit et al., 2014). The degree of pain is inversely proportional to comfort. The development of psycho-neuro-endocrine-immunology theory has led to the emergence of non-pharmacologic therapy (Gonzales-Diaz et.al., 2017).

Classical music is proven to cause relaxation (Yadak et al., 2017; Garza-Villarreal et al., 2014). It also has been used as a stimulant for the fetus. Other research also shows that classical music is the best type of music to relieve pain (Nwebube et al., 2017). However, it needs to be proven in hospital services through clinical research. Evidence of clinical research is expected to be consideration in establishing the standard 
procedures in patient with reduced consciousness to reduce pain. Besides, it might become a scientific basis for similar studies in the future.

\section{Method}

The population were adult patients $>18$ years old with reduced consciousness without a history of total deafness treated in the High Care Unit (HCU) of the UNS Hospital. The level of consciousness was determined based on the Glasgow Coma Scale with a score of 8 to 14 . The study subjects consisted of 18 patients, divided into 2 groups ( 9 patients per group), namely the control group who were not given an intervention $(\mathrm{C})$ and the intervention group with classical music treatment (M). The selected classical music was titled Moonlight Sonata in C-Sharp Min. OP27/21 ${ }^{\text {st }}$ Movement as a result of Ludwig van Beethoven's arrangement played on a piano instrument and played through an MP3 player.

One classical music intervention session has a duration of 36 minutes 46 seconds, given 3 times a day for 3 days at $7 \mathrm{am}, 3 \mathrm{pm}$ and $10 \mathrm{pm}$. The MP3 player volume was set at intensity \pm $73.05 \mathrm{~dB}$. The determination of noise was based on Occupational Safety and Health Administration standards $( \pm 90 \mathrm{~dB})$ which is safe for the human hearing exposed with a duration of less than 8 hours. The sound intensity of the independent variables was measured using the Sound Meter Application Android Physics Toolbox Suite version 1.9.2. The MP3 player is \pm 0.5 meters from the lateral side of the patient and is placed on a patient's bed or bed area that has a minimal risk of falling.

Pain scale assessment used the Critical Pain Observation Tool (CPOT) score and Behavioral Pain Scale Non-Intubated (BPS-NI) score. The pain scale assessment was carried out by three raters with an inter-rater reliability system. Inter-rater reliability in this study was measured statistically with Kappa Cohen's coefficient, with the following formula: $\mathrm{k}=(\mathrm{Po}-\mathrm{Pe}) /(1-\mathrm{Pe})$

$\mathrm{K}$ :Kappa Cohen's coefficient

Po :Relative agreement (accuracy) of observations between raters

$\mathrm{Pe}:$ :Hypothetical probability of an agreed coincidence

Kappa Cohen's coefficient interpretation (k) is as follows:

$0.01-0.20$ slight agreement

0.21 - 0.40 fair agreement
0.41 - 0.60 moderate agreement

0.61 - 0.80 substantial agreement

$0,81-1,00$ almost perfect or perfect agreement.

The calculation of interrater reliability aims to determine the Kappa Cohen's coefficient $(\mathrm{k})$. If $\mathrm{k}=0.01-0.80$ (slight to substantial agreement) is obtained, the CPOT and BPS-NI scores were taken from the average of CPOT and BPS-NI scores from the researchers and the average score of CPOT and BPS-NI from 2 interrater. If $\mathrm{k}$ $=0.81-1.00$ (almost perfect or perfect agreement) the CPOT and BPS-NI scores from the researcher were used.

Cortisol levels were measured by venous blood samples. As much as $5 \mathrm{~mL}$ of venous blood was taken from the median cubital vein as a legeartic procedure. It was carried out at 4 pm-5 pm on the 3rd day.

\section{Result and Discussion}

Table 1. CPOT and BPS-NI scores of pre-intervention and post-intervention

\begin{tabular}{ccccccc}
\hline \multirow{2}{*}{ Tool } & Group & $\mathrm{n}$ & $\begin{array}{c}\text { Pre } \\
\text { test }\end{array}$ & $\begin{array}{c}\text { Post } \\
\text { test }\end{array}$ & $\begin{array}{c}\text { Mean } \\
\text { difference }\end{array}$ & $\mathrm{P}$ \\
\hline CPOT & $\begin{array}{c}\text { Classical } \\
\text { music }\end{array}$ & 9 & 4.00 & 1.44 & 2.56 & 0.000 \\
& $\begin{array}{c}\text { Control } \\
\text { BPS-NI }\end{array}$ & 9 & 3.89 & 3.44 & 0.44 & 0.377 \\
& $\begin{array}{c}\text { Classical } \\
\text { music }\end{array}$ & 9 & 6.11 & 3.78 & 2.33 & 0.000 \\
& $\begin{array}{c}\text { Control } \\
\end{array}$ & 9 & 6.11 & 6.00 & 0.11 & 0.834 \\
\hline
\end{tabular}

As can be seen in table 1 and 2, the classical music group (M) experienced decreased CPOT average score by 2.56 and BPS-NI average score by 2.33. Meanwhile the control group (C) experienced decreased CPOT average score by 0.44 and BPS-NI average score by 0.11 . The average of decreased score in CPOT and BPS-NI in the $\mathrm{M}$ group was greater than in the $\mathrm{C}$ group.

The results shown in CPOT and BPS-NI score measurements showed that listening to classical music reduced the pain scale more than the control group. Statistically, significant differences occurred in the $M$ group with $p$ values $<0.05$ and did not occur in the control group.

Classical music had proven to have an influence in reducing pain and anxiety (Ghiasi, 2018; Lee, 2016). Patients with reduced consciousness can only treated by tactile-nociceptive, visual and auditory stimuli to regain their consciousness (Tortora and Derrickson, 2013). Sound waves that vibrate the hair cells in the cochlea will generate an action potential in the cochlear nerve and then to the 
primary auditory nucleus of the dorsalis et ventral gyrus and will continue as an ascending pathway of the lateral lemniscus to the inferior colliculus and the corpus geniculatum medialis. Finally, it ends to the primary auditory center in the Heschl transchalus temporalis gyrus (Brodmann areas of 41 and 42) through the radiatio auditius network. Those auditory ascending chains also have correlations with other areas such as the medial longitudinal fascia to the cerebellum for eye movements and conjugating the voice, the superior colliculus and the pretectal area for head response away from the voice, the ARAS to arouse awareness and the small branches leading to the hypothalamus-hypophysis (Baehr, 2012).

The signal in the form of an action potential of classical music is interpreted as a relaxation signal that causes the release of endogenous opioids ( $\beta$-endorphins, encephalins and dinorphins). The release of endogenous opioids is regulated by the relaxation center in the nucleus obliquus. These endogenous opioids then travel to $\mu, \mathrm{k}$ and $\delta$ receptors along the spinal cord, cerebral truncus and cerebrum, and result in analgesic effects, decreased respiratory rate and sedation (Benarroch, 2012).

Relaxation in the classical music group can also occur when auditory input shifts the signal of the prefrontal cortex from attention to pain signals to listening signals.

Table 2. Results of the cortisol measurements

\begin{tabular}{|c|c|c|c|c|c|}
\hline \multirow[t]{2}{*}{ No. } & \multicolumn{2}{|c|}{$\begin{array}{l}\text { Classical music } \\
\text { group }\end{array}$} & \multicolumn{2}{|c|}{ Controlled group } & \multirow[t]{2}{*}{$\mathrm{p}$} \\
\hline & Patient & $\begin{array}{c}\text { Cortisol } \\
\text { level } \\
(\mu \mathrm{g} / \mathrm{dL})\end{array}$ & Patient & $\begin{array}{c}\text { Cortisol } \\
\text { level } \\
(\mu \mathrm{g} / \mathrm{dL})\end{array}$ & \\
\hline 1. & M1 & 29.4 & K1 & 14.5 & \multirow[t]{9}{*}{0.694} \\
\hline 2. & M2 & 0.8 & K2 & 21.5 & \\
\hline 3. & M3 & 25.4 & K3 & 2.0 & \\
\hline 4. & M4 & 7.4 & K4 & 0.8 & \\
\hline 5. & M5 & 15.4 & K5 & 14.9 & \\
\hline 6. & M6 & 14.1 & K6 & 10.7 & \\
\hline 7. & M7 & 22.7 & K7 & 10.1 & \\
\hline 8. & M8 & 15.7 & K8 & 26.2 & \\
\hline 9. & M9 & 1.4 & K9 & 15.9 & \\
\hline & rage & 14.7 & & 12.96 & \\
\hline
\end{tabular}

As can be seen in table 2, measurements of cortisol levels showed no difference between $\mathrm{C}$ group and $M$ group $(p=0.694)$. However, the mean serum cortisol level was trending higher in the $M$ group $(14.7 \mu \mathrm{g} / \mathrm{dL})$, and was lower in the control group $(12.96 \mu \mathrm{g} / \mathrm{dL})$, although it was not statistically significant $(p=0.694)$.

The cortisol is a hormone that is responsible for stress conditions so that humans can maintain a state of homeostasis. Related to pain, cortisol is a hormone that inhibits pain. Classical music intervention can reduce hypothalamus-pituitary axis sympathetic tone (HPA) but does not directly reduce the release of cortisol and catecholamines. In this case, there is a negative feedback from the auditory pathway to the HPA axis, causing downregulation of cortisol and catecholamine release (Trappe, 2012; Mirghafourvand et al., 2016). This is consistent with the results of research by Hanafi et al. (2019) that there was no significant difference in the serum cortisol levels in 27 high care unit patients who were given a relaxing intervention.

\section{Conclusion and Suggestion}

Listening to classical music for patients with reduced consciousness decreased pain scale based on the CPOT and BPS-NI scores. This was supported by the average of blood cortisol levels that were higher trends in the classical music group, considering that cortisol is a hormone that prevents pain.

Based on the conclusions of this study, there is an opportunity to conduct research with similar methods with different intervention modalities, with additional intensity and duration. In addition, further research needs to be done to assess whether reduced consciousness due to structural lesions has the same response as non-structural lesions.

\section{Acknowledgments}

This research was funded by PNBP UNS 2018 Number: 259 / UN27 / HK / 2018. Thanks to the team of High Care Unit (HCU) at Universitas Sebelas Maret (UNS) Hospital for their cooperation during the research. Thank you to the Prodia laboratory for the good collaboration in the process of taking and examining blood of the research patients.

\section{References}

Baehr, M., Frotscher, M. and Duus, P. (2012). Duus' topical diagnosis in neurology: anatomy, physiology, signs, symptoms. Thieme.

Benarroch, E.E. (2012). Endogenous opioid systems: current concepts and clinical correlations. Neurology, 79(8), pp.807-814.

Garza-Villarreal, E.A., Wilson, A.D., Vase, L., Brattico, E., Barrios, F.A., Jensen, T.S.T., Romero-Romo, J.I. and Vuust, P., 2014. 
Music reduces pain and increases functional mobility in fibromyalgia. Front Psychol, 5, p.90.

Georgiou, E., Hadjibalassi, M., Lambrinou, E., Andreou, P. and Papathanassoglou, E.D. (2015). The impact of pain assessment on critically ill patients' outcomes: a systematic review. Biomed Res Int, 2015.

Ghiasi, A. and Keramat, A. (2018). The effect of listening to holy quran recitation on anxiety: A systematic review. Iran J Nurs Midwifery Res, 23(6), p.411.

González-Díaz, S.N., Arias-Cruz, A., Elizondo-Villarreal, B. and Monge-Ortega, O.P., 2017.

Psychoneuroimmunoendocrinology: clinical implications. World Allergy Organ J, 10(1), p.19.

Gorji, M.A.H., Araghiyansc, F., Jafari, H., Gorgi, A.M.H. and Yazdani, J. (2014). Effect of auditory stimulation on traumatic coma duration in intensive care unit of Medical Sciences University of Mazandarn, Iran. Saudi J Anaesth, 8(1), p.69.

Hanafi, M., Muhammad, F. and Wulandari, D. (2019). The Effect of Quran Recitation to Pain and Comfort Feeling on Patients with Reduced Consciousness in UNS Hospital. KnE Life Sci, pp.155-162.

Heiderscheit, A., Breckenridge, S.J., Chlan, L.L. and Savik, K. (2014). Music preferences of mechanically ventilated patients participating in a randomized controlled trial. Music Med, 6(2), p.29.

Lee, J.H. (2016). The effects of music on pain: a meta-analysis. J Music Ther, 53(4), pp.430-477.

Mirghafourvand, M., Shafaie, F.S., Mohammad-Alizadeh-Charandabi, S. and Jabbari, B. (2016). Effect of vocalization of the Holy Quran with and without translation on pregnancy outcomes: a randomized clinical trial. Iran Red Crescent Med J, 18(9).

Nwebube, C., Glover, V. and Stewart, L. (2017). Prenatal listening to songs composed for pregnancy and symptoms of anxiety and depression: a pilot study. BMC Complement Altern Med, 17(1), p.256.

Tortora, G.J. and Derrickson, B. (2013). Essentials of anatomy and physiology. Wiley.

Trappe, H.J., 2012. Role of music in intensive care medicine. Int J Crit Illn Inj Sci, 2(1), p.27.

Yadak, M., Ansari, K.A., Qutub, H., Al-Otaibi, H., Al-Omar, O., Al-Onizi, N. and Farooqi, F.A., 2019. The effect of listening to holy Quran recitation on weaning patients receiving mechanical ventilation in the intensive care unit: A Pilot Study. J Relig Health, 58(1), pp.64-73. 